\title{
Gene p53 Mutations Are Restricted to Poorly Differentiated and Undifferentiated Carcinomas of the Thyroid Gland
}

\author{
Rosangela Donghi, Alberto Longoni, Silvana Pilotti, * Paolo Michieli, Giuseppe Della Porta, and Marco A. Pierotti \\ Divisione di Oncologia Sperimentale A and * Divisione di Anatomia Patologica e Citologia, Istituto Nazionale Tumori, 20133 Milan, Italy
}

\begin{abstract}
The p53 gene was analyzed in tumor specimens obtained from 52 patients with various types of carcinoma of the thyroid gland by a combined molecular and immunocytochemical approach. The histologic types included 37 well-differentiated papillary and follicular carcinomas, 8 poorly differentiated, and 7 undifferentiated carcinomas. The p53 gene was shown to be unaffected in all differentiated tumors by single-strand conformation polymorphism analysis. However, in two out of eight (25\%) of poorly differentiated carcinomas and five out of seven (71\%) undifferentiated carcinomas, p53 mutations were identified and subsequently characterized by DNA sequencing. One undifferentiated carcinoma displayed two areas with varying degrees of differentiation. The comparative analysis of the p53 gene, in both the more and the less differentiated area of this tumor, clearly showed that the p53 mutation was confined to the latter component of the tumor specimen. These results indicate that mutations of the p53 gene are associated with the most aggressive histologic types of thyroid tumors, such as the undifferentiated carcinoma and, to a certain extent, the poorly differentiated carcinoma, and that the alterations of this gene represent a late genetic event in human thyroid carcinogenesis. (J. Clin. Invest. 1993.91:1753-1760.) Key words: immunocytochemistry • polymerase chain reaction • single-strand conformation polymorphism • tumor progression • tumor suppressor gene
\end{abstract}

\section{Introduction}

In the last few years, increasing evidence has indicated a central role of the p53 tumor suppressor gene in human carcinogenesis. In fact, p53 allelic losses or mutations are frequent genetic alterations in human cancers of different tissue origin, including those of the colon, lung, breast, brain, and hemopoietic tissue $(1,2)$.

The p53 mutations appear to be concentrated in a portion of the gene spanning exons 5-9, where the SV40 large-T binding domain and four evolutionary conserved regions map (3); a large variety of mutations has been observed in different codons covering these regions (1). Furthermore, the available data indicate that the occurrence of p53 mutations can be re-

Address reprint requests to Dr. Marco A. Pierotti, Divisione di Oncologia Sperimentale A, Istituto Nazionale Tumori, Via G. Venezian 1, 20133 Milan, Italy.

Received for publication 6 July 1992 and in revised form $10 \mathrm{No}$ vember 1992.

J. Clin. Invest.

(c) The American Society for Clinical Investigation, Inc.

0021-9738/93/04/1753/08 \$2.00

Volume 91, April 1993, 1753-1760 garded either as an early or a late event in tumor progression depending on the tumor type (4-6).

The tumors derived from the thyroid follicular epithelium comprise adenomas and carcinomas, the latter including the well-differentiated papillary and follicular types and the undifferentiated type. The well-differentiated carcinomas (WDCs) ${ }^{1}$ are characterized by a low biological aggressiveness and an indolent course, whereas the undifferentiated carcinomas (UCs) display aggressive behavior with rapid fatal outcome $(7,8)$. More recently, on the basis of several reports on differentiated carcinomas showing a more pronounced aggressiveness, the existence of a group of so-called poorly differentiated carcinomas (PDCs) with a prognosis intermediate between that of differentiated and undifferentiated subtypes was identified (912).

In spite of their common histogenic origin but in agreement with their different biologic and clinical features, the pathogenesis of the various histologic types appears to be associated with the occurrence of different genetic events. In fact, among differentiated carcinomas it has been determined that a frequent activation of ras oncogenes is present in all the stages of progression from follicular adenoma to follicular and UCs (13-15), whereas in papillary thyroid carcinomas the two genes $r e t$ and Ntrk1 (proto trk), whose products display all the features of a receptor tyrosine kinase, are activated in $\sim 50 \%$ of the analyzed cases (16-20). In addition, two recent studies have investigated the role of p53 in thyroid tumors with contrasting results. Wright et al. (21), in analyzing about 100 WDCs and 20 UCs found only one case of follicular carcinoma with p53 mutation. On the contrary, Ito et al. (22), by analyzing 10 differentiated and 7 undifferentiated thyroid tumors, found p53 mutations in $\sim 85 \%$ of UCs.

To clarify this issue, we investigated for the presence of $\mathrm{p} 53$ mutations a series of thyroid carcinomas both by molecular and immunocytochemical analysis. The results suggest that p53 mutations are restricted to the more aggressive histologic types and are associated with both dedifferentiation and progression.

\section{Methods}

Tumor storage and DNA extraction. Surgical specimens of thyroid carcinomas were frozen in isopentane precooled by liquid nitrogen as well as formalin-fixed and paraffin-embedded. High molecular weight DNA extraction from normal and tumor samples was performed as previously reported (16).

Single-strand conformation polymorphism (SSCP) analysis. Oligonucleotide primers for both the SSCP and DNA sequencing were described by Gaidano et al. (23). The couples of primers were chosen in

1. Abbreviations used in this paper: $\mathrm{PDC}$, poorly differentiated carcinoma; SSCP, single-strand conformation polymorphism; UC, undifferentiated carcinoma; WDC, well-differentiated carcinoma. 
order to amplify the exons $5,6,7,8$, and 9. SSCP was accomplished according to an adapted version of the method described by Gaidano et al. (23). The PCR reaction was performed with $100 \mathrm{ng}$ of genomic DNA, 5 pmol of each primer, $2.5 \mu \mathrm{M}$ each of dATP, dTTP, dGTP, $2.17 \mu \mathrm{M}$ of dCTP, $5 \mu \mathrm{Ci}$ of $\left[\alpha{ }^{32} \mathrm{P}\right] \mathrm{dCTP}$ (Amersham International, Amersham, UK; $3,000 \mathrm{Ci} / \mathrm{mmol}$ ), $10 \mathrm{mM}$ Tris $\mathrm{HCl}$ ( $\mathrm{pH} 8.8$ ), $50 \mathrm{mM}$ $\mathrm{KCl}, \mathrm{MgCl}_{2} 1 \mathrm{mM}$ (for exons 5, 6, 7, and 9) or $1.3 \mathrm{mM}$ (for exon 8 ), $0.01 \%$ gelatin, $0.5 \mathrm{U}$ of Taq DNA polymerase (Cetus-Perkin Elmer, Norwalk, CT) in a final volume of $5 \mu \mathrm{l}$. The amplification, consisting in 30 cycles of denaturation $\left(95^{\circ} \mathrm{C}, 1 \mathrm{~min}\right)$, annealing $\left(58^{\circ} \mathrm{C}, 30 \mathrm{~s}\right.$ for exon $8 ; 63^{\circ} \mathrm{C}, 30$ s for exons $5,6,7$, and 9$)$, and extension $\left(72^{\circ} \mathrm{C}, 1\right.$ min), was performed on an automated thermal cycler (Cetus-Perkin Elmer). The reaction mixture $(5 \mu \mathrm{l})$ was diluted $1: 80$ by adding $395 \mu \mathrm{l}$ of $0.1 \%$ SDS, $10 \mathrm{mM}$ EDTA; $2 \mu \mathrm{l}$ of the dilution was then mixed with $18 \mu \mathrm{l}$ of sequencing stop solution (95\% formamide, $20 \mathrm{mM}$ EDTA, $0.05 \%$ bromophenol blue, $0.05 \%$ xylene cyanol) containing $20 \mathrm{mM}$ $\mathrm{NaOH}$. Samples were heated at $95^{\circ} \mathrm{C}$ for $5 \mathrm{~min}$, chilled on ice, and immediately loaded onto a $8 \%$ polyacrylamide- $1 \times$ Tris-borate/EDTA (TBE) gel containing $10 \%$ glycerol ( $7 \%$ polyacrylamide $/ 4 \%$ glycerol for the only exon 6). Gels were run at $8 \mathrm{~W}$ for $16-20 \mathrm{~h}$ at room temperature, fixed in $10 \%$ acetic acid, $10 \%$ methanol for $20 \mathrm{~min}$, and then vacuum-dried. Autoradiography was performed at $-80^{\circ} \mathrm{C}$ with intensifying screens for 4-72 $\mathrm{h}$.

Sequencing. PCR products purified on gel were utilized as template in direct sequencing reactions. Sequencing was performed with $\left[\alpha-{ }^{35} S\right]-$ dATP as label, using a Sequenase kit (United States Biochemical Corp., Cleveland, $\mathrm{OH}$ ) according to the manufacturer's recommended protocols, or by reamplification with Taq polymerase and $\left[5^{\prime}-{ }^{32} \mathrm{P}\right]$-labeled primers as specified below.

2 pmol of the primer were 5 ' end-labeled by $5 \mathrm{U}$ of $\mathrm{T} 4$ polynucleotide kinase (New England Biolabs, Beverly, MA) in $5 \mu$ l of a reaction mixture containing: 2 pmol of $\left[\gamma-{ }^{32} \mathrm{P}\right] \mathrm{ATP}$ (Amersham International; $5,000 \mathrm{Ci} / \mathrm{mmol}$ ), $50 \mathrm{mM}$ Tris $\mathrm{HCl}$ (pH 7.6), $10 \mathrm{mM} \mathrm{MgCl}, 5 \mathrm{mM}$ DTT, $0.1 \mathrm{mM}$ spermidine, $0.1 \mathrm{mM}$ EDTA ( $\mathrm{pH} 8.0$ ). The reaction mixture was incubated at $37^{\circ} \mathrm{C}$ for $30 \mathrm{~min}$, then at $68^{\circ} \mathrm{C}$ for $10 \mathrm{~min}$. For sequencing, purified amplified DNA was reamplified in the presence of one labeled primer, the four dNTPs, and one of the four ddNTPs (24). The reaction mixture (final volume $10 \mu \mathrm{l}$ ) contained 0.05 pmol of DNA, $0.05 \mathrm{pmol}$ of labeled primer, $0.5 \mathrm{U}$ of Taq polymerase, $10 \mu \mathrm{M}$ of each dNTP, $250 \mu \mathrm{M}$ ddATP or $30 \mu \mathrm{M}$ ddGTP, or 200 $\mu \mathrm{M}$ ddCTP or $250 \mu \mathrm{M}$ ddTTP, $50 \mathrm{mM}$ Tris $\mathrm{HCl}, \mathrm{pH} 8.8,7 \mathrm{mM} \mathrm{MgCl}_{2}$, $0.05 \%$ NP-40, and $0.05 \%$ Tween 20 .

18 cycles were executed with a denaturation $\operatorname{step}\left(95^{\circ} \mathrm{C}, 1 \mathrm{~min}\right)$, an annealing step $\left(58^{\circ} \mathrm{C}, 30 \mathrm{~s}\right.$ for exon $8 ; 63^{\circ} \mathrm{C}, 30 \mathrm{~s}$ for exons $5,6,7$, and 9 ), and an extension step $\left(72^{\circ} \mathrm{C}, 2 \mathrm{~min}\right)$. Reactions were electrophoresed on $6 \%$ polyacrylamide $/ 7.67 \mathrm{M}$ urea/ $1 \times \mathrm{TBE}$ gel. When a tumor sample containing p53 mutation was identified, the result was confirmed by repeating the entire procedure: amplification of genomic DNA, fragment purification, and sequencing. To verify the tumor-associated nature of the observed p53 alterations, we analyzed by SSCP and/or by sequencing the homologous region of the $p 53$ gene from the relative peripheral blood lymphocytes DNA of the cases displaying a mutated p53 in tumor sample.

Histology. In this study the term "poorly differentiated carcinoma" was used to classify differentiated carcinomas recently reported as carcinoma with intermediate malignancy, i.e., insular carcinoma (10), tall cell variant of papillary carcinoma (11), trabecular subtype of papillary carcinoma (12), and PDC according to Sakamoto et al. (9). UCs were classified according to World Health Organization criteria (25).

Immunocytochemistry. Immunocytochemical staining of the p53 protein on frozen sections was carried out by the avidin-biotin complex technique with or without S-diaminobenzidine silver enhancement according to Frigo et al. (26) using the monoclonal antibody PAb240 at a dilution of $1: 2,000$ or $1: 100$, respectively. This antibody was raised against mutant forms of p53, but by immunocytochemistry it recognizes also the normal protein (27). On paraffin-embedded sections, immunocytochemistry was performed using the polyclonal antiserum
Table I. Gene p53 Mutations and Histological Type of Thyroid Carcinoma

\begin{tabular}{|c|c|c|}
\hline Histological type & $\begin{array}{l}\text { p53 mutations/ } \\
\text { total cases }\end{array}$ & Frequency \\
\hline & $n$ & $\%$ \\
\hline Differentiated papillary & $0 / 33^{*}$ & - \\
\hline Differentiated follicular & $0 / 4^{\ddagger}$ & - \\
\hline Poorly differentiated & $2 / 8^{\S}$ & $25)$ \\
\hline Undifferentiated & $5 / 7^{11}$ & $71\}^{47}$ \\
\hline Total & $7 / 52$ & 13 \\
\hline
\end{tabular}

* Among these cases, 13 cases showed ret gene activation, 6 trk gene activation, and $1 \mathrm{H}$ ras gene activation, and 13 were negative for oncogenes activation.

$\ddagger$ Two of these cases showed ras gene activation and two were negative for oncogenes activation.

${ }^{\$}$ Among these cases, three showed ras gene activation, two were negative for oncogenes activation, and three were not analyzed.

"Among these cases, three were negative for oncogenes activation and four were not analyzed.

CM-1 raised against wild-type human p53 (Novocastra Laboratory, Newcastle, UK), but recognizing also the mutated protein, using a modification (28) of the method described by Shi et al. (29). The two antibodies, irrespective of whether they were generated against mutated or wild-type $\mathrm{p} 53$, recognize a form of the protein whose half-life was increased by tumor-associated $\mathrm{p} 53$ gene alterations. They do not react with normal cells because of the physiologically short half-life of the $\mathrm{p} 53$ protein (2).

\section{Results}

SSCP analysis of p53 gene. We examined by SSCP analysis a total of 52 DNA from 37 WDCs ( 33 papillary and 4 follicular),

\section{exon 5 exon $6 \quad$ exon 7}

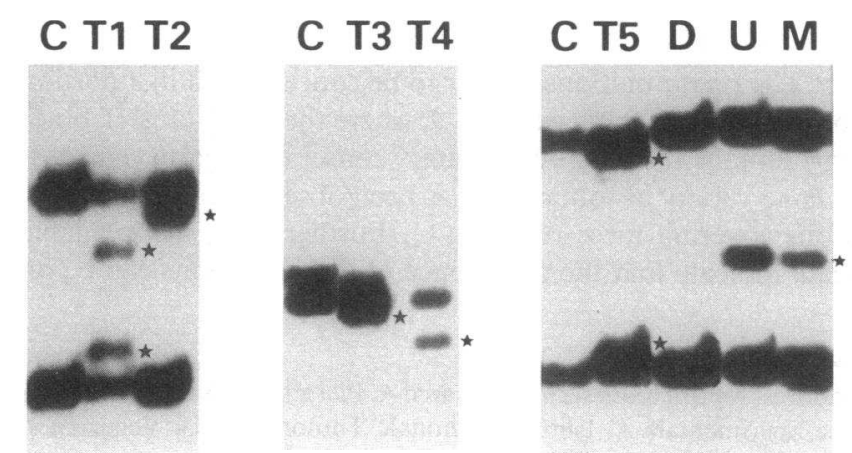

Figure 1. SSCP analysis of exons 5, 6, and 7 of the p53 gene in thyroid samples. $C$, control DNA displaying wild-type exons; $T 1-T 6$, thyroid cancer DNA samples with mobility shifts (the shifted bands are indicated by $a ; D$ and $U$, DNA samples from the differentiated and the undifferentiated portion of the primary tumor from patient T6, respectively; $M$, DNA sample from lymph-nodal metastasis from the same patient. 


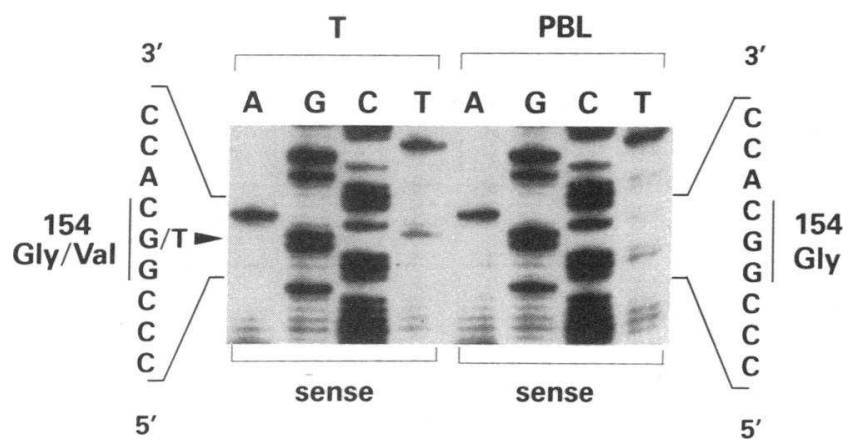

Figure 2. Nucleotide sequence analysis of a portion of p53 exon 5 from tumor $(T)$ and peripheral blood lymphocytes $(P B L)$ DNA of patient T1. The normal CGG sequence of the codon 154 is shown in the right panel. In the left panel are present both a $\mathrm{G}$ and a $\mathrm{T}$ ( $a r$ rowhead) at this position, indicating both mutant and normal alleles in the tumor sample.

8 PDCs, and 7 UCs. A previous analysis of 45 of these DNA by transfection assay and/or by molecular techniques revealed that 13 WDCs of the papillary type did not show an activation of dominant oncogenes, 13 were positive for ret, 6 for $t r k 1$ transforming rearrangements, and 1 displayed a mutation of Nras; similarly, whereas two follicular carcinomas were negative, other two tumors of the same histotype showed Hras and Nras mutation, respectively $(17,18,20$, and unpublished results). Among the PDCs and UCs, five were negative and in three cases a mutation of one of each member $(\mathrm{N}, \mathrm{H}$, and $\mathrm{K})$ of the ras oncogene family was identified (Table $\mathrm{I}$ ).

The SSCP analysis revealed the occurrence of p53 gene alteration in four of the WDCs (data not shown). However, the subsequent sequence analysis of the affected exon showed that the mutated samples belonged to heterozygous individuals carrying a p53 allele with a silent mutation in exon 6 at codon 213 , which defines a previously described constitutional genetic polymorphism $(30,31)$. Therefore, this analysis shows that none of the WDCs analyzed, irrespective of the activation of a dominant oncogene, displayed a p53 gene alteration ( Table I).

On the contrary, $\sim 50 \%$ of the 15 samples of PDCs and UCs, showed an alteration of one p53 exon (Table I). The results of the SSCP analysis of six out of the seven mutated samples are shown in Fig. 1. Two mutations mapped in exon 5 ( $\mathrm{T} 1$ and $\mathrm{T} 2$ ), two in exon 6 (T3 and T4), two in exon 7 (T5 and T6), and one, not shown in the figure, in exon 8 (T7). In the majority of the mutated samples, the SSCP analysis showed the presence of both variant bands, corresponding to a mutated p53 allele, and of bands related to the wild-type one. From case 6 , an UC, three different specimens were available, two (D and $\mathrm{U}$ ) representing different areas of the primary tumor (a more and a less differentiated area, respectively), and the third one relative to a lymph-nodal metastasis. As it can be seen in Fig. 1, the more differentiated portion of the tumor (D) showed only the migration pattern of the wild-type exon 7 , while both the less differentiated portion of the tumor $(U)$ and the metastatic


Figure 3. Nucleotide sequence analysis of portions of p53 exons 5, 6, and 7 from tumor DNA of patients T2 $(A)$, T3 $(B)$, T4 (C), and T5 $(D)$. In $D$ the mutated sequence is compared to the wild-type exon 7 from normal control DNA. All the tumor samples show the deletion of one ( $B$ and $D)$ or two $(A$ and $C)$ bases. The deleted bases are indicated in heavy type $(A, B$, and $C)$ or by $\Delta(D)$. In all samples are present both the deleted and the wild-type alleles. In $B$ is shown the silent mutation at codon 213 . 


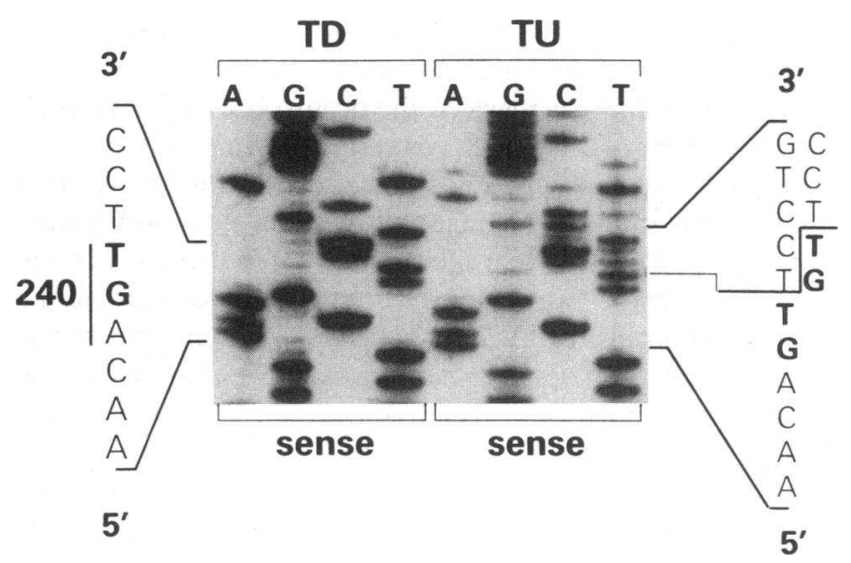

Figure 4. Nucleotide sequence analysis of a portion of p53 exon 7 from a more differentiated $(T D)$ and an undifferentiated $(T U)$ area of the same tumor specimen from patient $T 6$. The undifferentiated area shows the presence of an heterozygous dinucleotide duplication (GT) at codon 240; the more differentiated counterpart displays only wild-type p53 exon 7 .

sample (M) displayed also a band with altered electrophoretic mobility, suggesting the presence of a mutated p53 allele.

Nucleotide sequence analysis of p53 gene mutations. To characterize the $\mathrm{p} 53$ gene mutations detected by SSCP analysis, we determined the nucleotide sequence of the identified mutated samples by direct sequencing of the PCR-amplified exons. The results of our analysis, shown in Figs. 2, 3, and 4 and summarized in Table II, revealed a peculiar pattern of p53 alterations. In fact, whereas in the majority of the studies the most frequent p53 alteration reported was a point mutation (1), we found only two cases (T1 and T7) with such an alteration. Fig. 2 shows the mutation $(G \rightarrow T)$ detected in sample
T1. Four other cases displayed a deletion of one or two bases (samples T2, T3, T4, and T5; Fig. 3) and another sample showed a dinucleotide duplication (sample T6; Fig. 4). Both the deletions and the duplication resulted in frameshift potentially coding for truncated forms of the p53 product (Table II). The reasons for this unusually high frequency of this kind of p53 gene alterations are not immediately evident.

In peripheral blood lymphocytes of all the patients whose tumors showed a mutated p53 gene, only the p53 wild-type sequence was detected. The lymphocytes of case T7 were not available. Fig. $3 \mathrm{~B}$ shows, in the antisense strand, that tumor N. 3 contained also the silent mutation CGA/CGG at codon 213 that, as previously reported, we found also in four differentiated carcinomas and that was related to a constitutional genetic polymorphism.

Both SSCP and sequencing analyses revealed that in the majority of the samples the wild-type p53 sequence was clearly retained. At present, we cannot determine whether the normal allele resulted from a cellular heterogeneity of the samples (normal and tumor cells) as was apparent in case 5, or by a heterozygosity for the p53 mutations. Sequencing data from case 6, reported in Fig. 4, confirmed the observations obtained by SSCP. In fact, whereas the samples from the undifferentiated portion of the primary tumor (Fig. 4, right panel) and the metastasis (data not shown) displayed the same p53 alteration (GT duplication at codon 240), the analysis of the DNA from the more differentiated area of the same tumor detected only wild-type p53 sequence (Fig. 4, left panel).

Histology and immunocytochemical analysis. The case material consisted of seven UCs and eight PDCs. Undifferentiated carcinomas included the following types: three spindle cell, three giant cell, and one small cell. In three of these tumors a residual well-differentiated component was present. PDCs were made up of the following types: three insular, three tall cell, one trabecular, and one poorly differentiated.

Table II. Gene p53 Mutations in Poorly Differentiated and Undifferentiated Thyroid Carcinomas

\begin{tabular}{|c|c|c|c|c|c|}
\hline Tumor & $\mathrm{PDC} / \mathrm{UC}$ & Exon & Codon & Mutation & Amino acid \\
\hline $\mathrm{T} 1$ & PDC & 5 & 154 & $\begin{array}{l}\text { GGC } \rightarrow \text { GTC } \\
\quad(\text { point mutation) }\end{array}$ & Gly $\rightarrow$ Val \\
\hline $\mathrm{T} 2$ & UC & 5 & $170-171$ & $\begin{array}{l}\text { ACGGAG } \rightarrow \text { AC } \triangle \triangle A G \\
\text { (deleted GG) }\end{array}$ & frameshift \\
\hline $\mathrm{T} 3$ & UC & 6 & 208 & $\begin{array}{l}\mathrm{GAC} \rightarrow \mathrm{G} \Delta \mathrm{C} \\
\quad(\text { deleted } \mathrm{A})\end{array}$ & frameshift \\
\hline $\mathrm{T} 4$ & UC & 6 & 209 & $\begin{array}{l}\mathrm{AGA} \rightarrow \Delta \Delta \mathrm{A} \\
\quad(\text { deleted } \mathrm{AG})\end{array}$ & frameshift \\
\hline T5 & PDC & 7 & 241 & $\begin{array}{r}\mathrm{TCC} \rightarrow \mathrm{T} \Delta \mathrm{C} \\
(\text { deleted } \mathrm{C})\end{array}$ & frameshift \\
\hline T6D & UC & 7 & 240 & wild type & wild type \\
\hline T6U & UC & 7 & 240 & 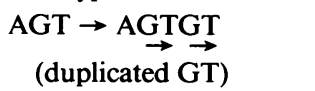 & frameshift \\
\hline T6M & UC & 7 & 240 & $\begin{array}{l}\text { AGT } \rightarrow \underset{\text { AGTGT }}{\rightarrow} \underset{(\text { duplicated GT) }}{\rightarrow}\end{array}$ & frameshift \\
\hline T7 & UC & 8 & 272 & $\begin{array}{l}\text { GTG } \rightarrow \text { TTG } \\
\quad(\text { point mutation) }\end{array}$ & Val $\rightarrow$ Leu \\
\hline
\end{tabular}

From case 6, three samples were analyzed: two represented more (D) and less differentiated (U) areas of the primary tumor, respectively, and the third was a lymphnodal metastases (M). 
Table 3. Clinical Data: Pathologic Stage and Gene p53 Mutations in PDCs and UCs

\begin{tabular}{|c|c|c|c|c|c|c|c|c|}
\hline \multirow[b]{2}{*}{ Patient } & \multirow[b]{2}{*}{ Age } & \multirow[b]{2}{*}{ Sex } & \multirow[b]{2}{*}{$\begin{array}{l}\text { Histologic } \\
\text { type }\end{array}$} & \multicolumn{2}{|c|}{ Pathologic stage (pTNM)* } & \multirow[b]{2}{*}{ Follow-up } & \multicolumn{2}{|c|}{$\mathrm{p} 53$} \\
\hline & & & & At presentation & Recurrence & & $\begin{array}{c}\text { Reactivity } \\
\text { with pAb240 }\end{array}$ & $\begin{array}{c}\text { Presence of } \\
\text { mutation }\end{array}$ \\
\hline & & & & & $(m o)$ & $(m o)$ & & \\
\hline T1 & 53 & $\mathrm{~F}$ & PDC & pT4N1a(R2), M+ (PUL, OSS) & UN & Lost & +1 & + \\
\hline $\mathrm{T} 2$ & 38 & $\mathrm{~F}$ & UC & pT4N0M0 & UN & Lost & $+* *$ & + \\
\hline T3 & 59 & $\mathrm{~F}$ & UC & pT4N0M0 & - & $\mathrm{A}, \mathrm{DF},(72)$ & - & + \\
\hline $\mathrm{T} 4$ & 73 & $\mathbf{M}$ & UC & pT4M+ (PUL, OSS) & - & DOD, (UN) & $+\$$ & + \\
\hline T5 & 43 & $\mathbf{M}$ & PDC & pT4N0M+ (OSS) & - & $A, W D,(36)$ & $+\$ 8$ & + \\
\hline T6 & 56 & $\mathbf{M}$ & UC & pT4N1aM+ $(\mathrm{OTH})^{\ddagger}$ & - & $A, W D,(7)$ & $++^{\ddagger}$ & + \\
\hline $\mathrm{T7}$ & 75 & $\mathbf{F}$ & UC & pT4N1a (R2) M0 & local progression" & DOD, (2) & $++^{\ddagger \ddagger}$ & + \\
\hline $\mathrm{T} 8$ & 77 & $\mathrm{~F}$ & PDC & pT4N0M0 & - & $\mathrm{A}, \mathrm{DF},(9)$ & - & - \\
\hline T9 & 56 & $\mathbf{M}$ & PDC & pT4N0M0 & Nla (12) & $\mathrm{A}, \mathrm{DF},(24)$ & - & - \\
\hline $\mathrm{T} 10$ & 65 & F & PDC & pT4N1aM0 & $\mathrm{M}+(\mathrm{OSS}, \mathrm{SKI})(24)$ & $A, W D,(6)$ & - & - \\
\hline $\mathrm{T} 11$ & 52 & $\mathbf{M}$ & UC & $\mathrm{rpT} 4^{\S}$ & NlaM+ (PUL) (70) & DOD, (72) & - & - \\
\hline $\mathrm{T} 12$ & 51 & $\mathrm{~F}$ & PDC & pT4N1bM+ (OSS) & UN & Lost & - & - \\
\hline $\mathrm{T} 13$ & 54 & $\mathbf{F}$ & UC & pT4N1aM+ (OSS) & - & $A, W D,(12)$ & - & - \\
\hline $\mathrm{T} 14$ & 60 & $\mathbf{F}$ & PDC & rpT2N1M+(OSS, PUL) & - & $A, W D,(3)$ & - & - \\
\hline T15 & 64 & $\mathbf{M}$ & PDC & $\mathrm{rpN} 1 \mathrm{a}^{\S}$ & local progression" & $A, W D,(2)$ & - & - \\
\hline
\end{tabular}

Abbreviations: A, alive; DF, disease free; UN, unknown; WD, with disease; DOD, dead of disease.

* Shorthand according to TNM system (Hermanek and Sobin [35]).

* Adrenal gland.

${ }^{5}$ First surgical treatment elsewhere 6 (T11), 3 (T14), and 2 (T15) mo before.

"Laryngeal infiltration.

' PDC, poorly differentiated type (Sakamato et al. [9]).

** UC, spindle-cell variant with residual differentiated component.

${ }^{\ddagger} \mathrm{UC}$, giant-cell variant (T4 and T7) with residual differentiated portion (T6).

$\$$ PDC, insular type.

On frozen sections, positive staining with PAb240 was observed on six out of the seven cases in which a molecular alteration of $\mathrm{p} 53$ gene had been detected (Table III). The reactivity covered the whole sample in two cases of UC (T7 and T4) (an example is given in Fig. 5) and in one PDC (T1). In these samples $>80 \%$ of the nuclei were p53 positive. In the remaining positive cases, a selective distribution of nuclear immunostaining was detected in almost all tumoral cells belonging to sharply defined, less differentiated areas. Confirming the molecular findings, case T6 showed immunoreactivity restricted to the undifferentiated component of the tumor.

On paraffin-embedded samples, the CM-1 antiserum confirmed these results (Fig. 5), and in two cases, T2 and T5, permanent sections showed better defined structural details compared to frozen sections. In the first case, a strong nuclear immunostaining was shown throughout the undifferentiated component only, whereas the surrounding more differentiated areas were either negative or displayed scattered foci of cells with weak nuclear reactivity (Fig. 6). In the second case, sharply defined areas of immunoreactivity were restricted to tumor tissue which showed a poorly differentiated pattern and evidence of aggressive growth, such as capsular invasion, neoplastic embolization within the tumor, and evidence of infiltration at the periphery (Fig. 7).

As shown in Table III, the seven $\mathrm{p} 53$ positive tumors, including the one positive only by molecular analysis (T3), were stage pT4 and in two of them radical surgery could not be achieved. In addition, in four patients there were distant metastases at presentation and local progression at relapse in one patient.

\section{Discussion}

We analyzed for the presence of p53 gene mutations DNA samples from well-differentiated, poorly differentiated, and undifferentiated thyroid carcinomas. The results clearly indicate that p53 gene alterations do not represent a common genetic hallmark of thyroid carcinomas. In fact, none of the 37 WDCs analyzed showed abnormal electrophoretic behavior after SSCP analysis of p53 exons 5-9. On the contrary, 7 out of the 15 PDCs and UCs were found to exhibit a mutated p53 gene by molecular and/or immunocytochemical techniques.

Ito et al. (22) recently reported similar results by direct sequencing of p53 exons 5-8 from 17 thyroid samples, including differentiated papillary adenocarcinomas and UCs. They did not find any p53 mutation in differentiated tumors, but six out of seven UCs were found to carry p53 mutations.

In contrast with these findings, Wright et al. (21), who analyzed 129 thyroid tumor samples (including follicular adenomas, follicular and papillary carcinomas, and UCs) mainly by immunocytochemistry, detected the mutation of the p53 gene only in one differentiated thyroid carcinoma from which a continuous cell line was established. In contrast to colon, breast, and lung carcinomas, p53 alterations do not seem to 

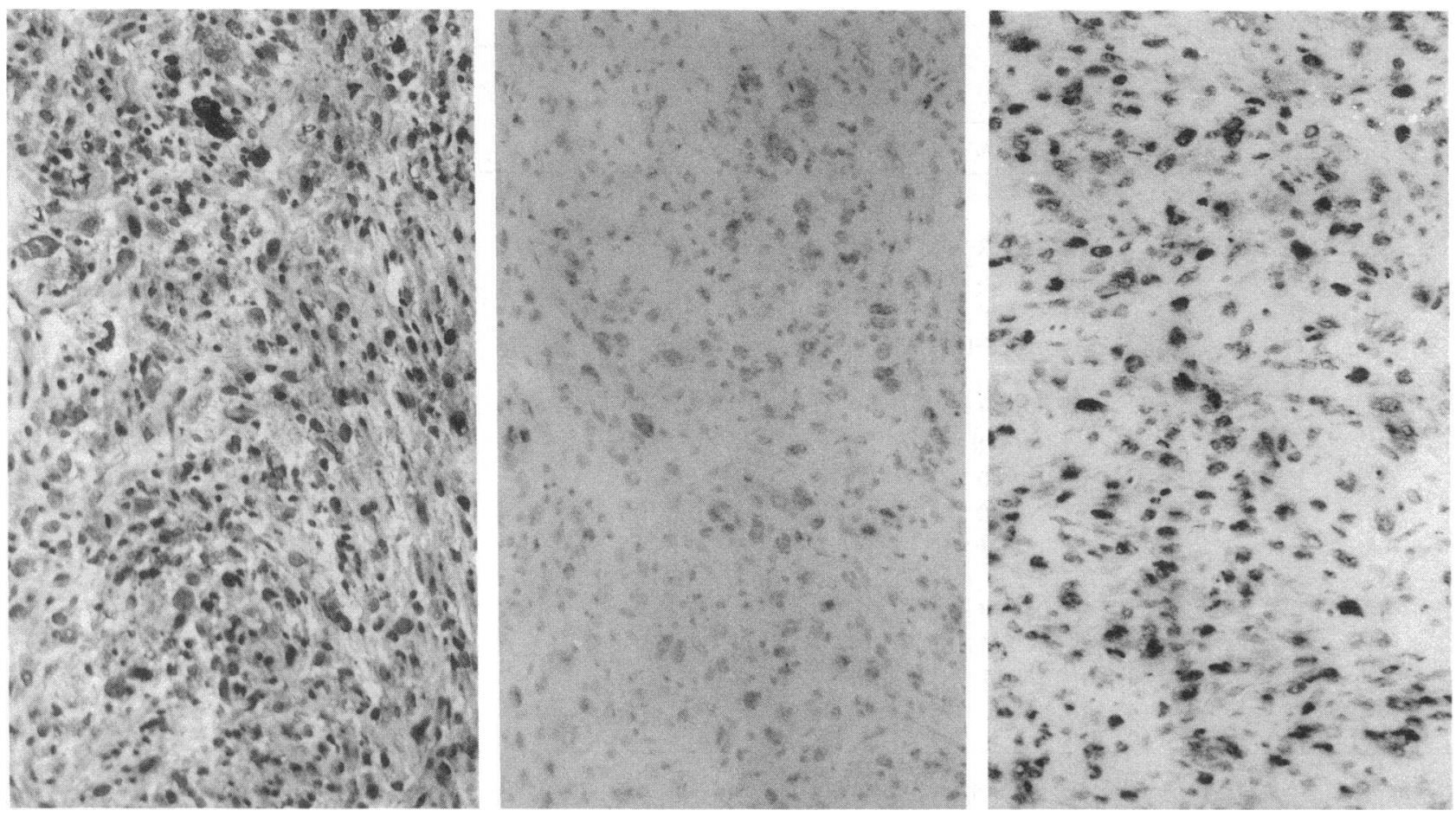

Figure 5. Immunostaining using both PAb240 and CM-1 antibodies on sections of tumor T7. Left: anaplastic pattern of the tumor (H\&E $\times 80)$. Middle: uniformly weak nuclear reactivity with PAb240. Right: strong nuclear reactivity with CM-1.

play a significant role in thyroid carcinomas. Several factors could explain the discrepancy between these results and the above reported findings by Ito et al. (22) and our present analysis. Owing to the small number of cases analyzed in each report, it is not possible to exclude sampling bias. As already reported for other genetic alterations found in thyroid carcinomas such as ras mutations (15) and ret rearrangements (18), the results might have been significantly affected by the different geographical origin of the tumors analyzed. Other differences in the experimental approach might also have contrib- uted to these divergent results. In fact, all our cases of PDCs and UCs were analyzed by immunocytochemistry and by SSCP, and the affected exons were sequenced, whereas only 4 out of the 20 cases reported by Wright et al. (21) were analyzed in a similar way. In addition, these authors did not analyze p53 exon 6, where both we and Ito found some mutations.

Although it is generally accepted that a positive correlation exists between $\mathrm{p} 53$ abnormalities detected by molecular and immunocytochemical techniques, discrepancies between the two approaches may occur in both directions (32). Also in our

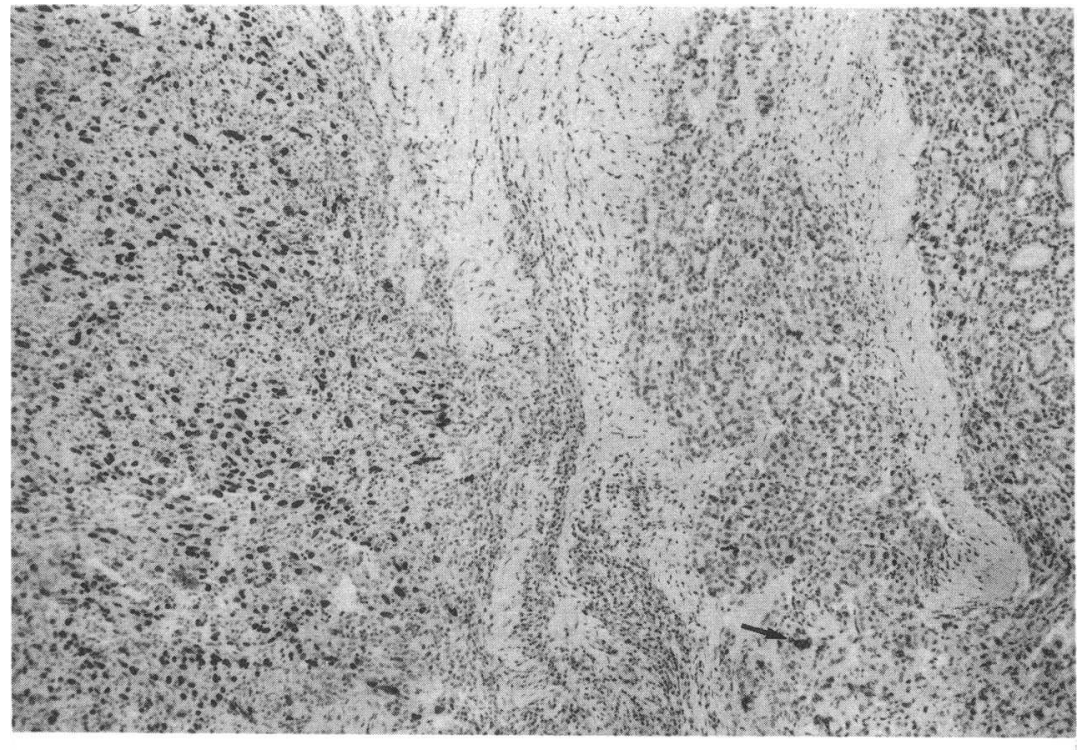

Figure 6. UC. Immunostaining using CM-1 on paraffin-embedded material from tumor $\mathrm{T} 2$. The strong reactivity is confined to the nuclei of the undifferentiated component. Scattered, less intensely reactive nuclei are visible (arrow) throughout the adjacent more differentiated areas $(\times 63)$. 


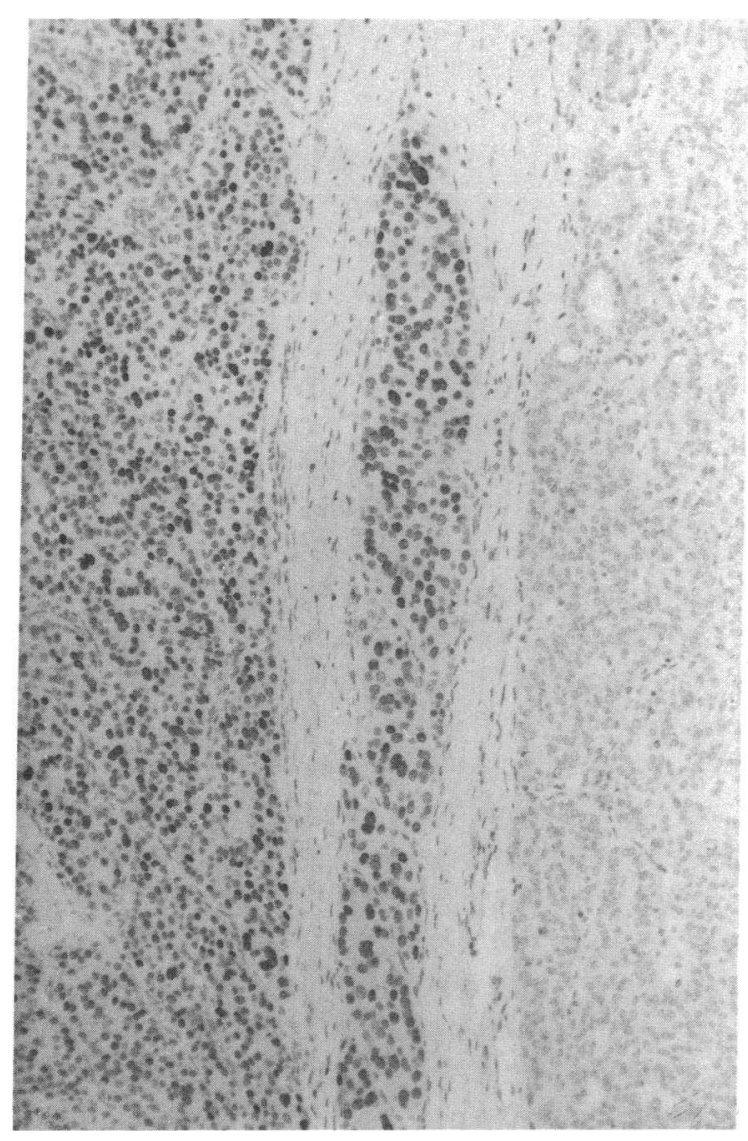

Figure 7. PDC. Immunostaining using CM-1 on paraffin-embedded material from tumor $\mathrm{T} 5$. The marked reactivity is sharply confined to the less differentiated component and to the intravascular growth within the tumor $(\times 110)$.

analysis, one case showed a p53 deletion in exon 6 without immunocytochemical counterpart.

In spite of this limitation our results clearly indicate that p53 alteration is associated with poorly differentiated and undifferentiated types of carcinoma of the thyroid gland and, most likely, with the progression of the tumor. In fact, in three cases where different stages of tumor evolution were recognizable, the comparison of the $\mathrm{p} 53$ immunostaining with the histological characteristics showed a selective distribution of the immunoreactivity to the more active growth fraction in PDCs and the anaplastic component in UCs. The area-to area heterogeneity linked to the close association between the intensity of the immunostaining and the morphological features of definite aggressiveness and dedifferentiation within each of the two histologic types investigated suggests that alterations of p 53 may be related to both the aquisition of invasive properties and loss of differentiation. Moreover, when the molecular analysis was performed separately on differentiated and undifferentiated areas of the same carcinoma, we found the $\mathrm{p} 53$ alterations to be associated only with the latter.

Altogether, these observations are in agreement with the previously suggested concept that both PDCs and UCs may derive from the progression of preexisting differentiated carci- nomas $(33,34)$ and that $p 53$ mutations represent a late genetic event in human thyroid carcinogenesis.

\section{Acknowledgments}

The authors thank Mrs. Giovanna Raineri for manuscript preparation, Miss Sally Clegg for manuscript revision, Mrs. Maria Teresa Radice for oligonucleotides synthesis, and Mr. Mario Azzini for photographic assistance. The advice and critical review of Professor Franco Rilke is also acknowledged.

This work was supported by grants from the Associazione Italiana Ricerca Cancro and from the CNR Special Project "ACRO."

\section{References}

1. Hollstein, M., D. Sidransky, B. Vogelstein, and C. C. Harris. 1991. p53 mutations in human cancers. Science (Wash. DC). 253:49-53.

2. Levine, A. J., J. Momand, and C. A. Finlay. 1991. The p53 tumor suppressor gene. Nature (Lond.). 351:453-456.

3. Soussi, T., C. Caron de Fromentel, and P. May. 1990. Structural aspects of the p53 protein in relation to gene evolution. Oncogene. 5:945-952.

4. Chiba, I., T. Takahashi, M. M. Nau, D. D’Amico, D. T. Curiel, T. Mitsudomi, D. L. Buchhagen, D. Carbone, S. Piantadosi, H. Koga, et al. 1990. Mutations in the p53 gene are frequent in primary, resected non-small cell lung cancer. Oncogene. 5:1603-1610.

5. Mazars, R., P. Pujol, T. Maudelonde, P. Jeanteur, and C. Theillet. 1991. p53 mutations in ovarian cancer: a late event? Oncogene. 6:1685-1690.

6. Sidransky, D., T. Mikkelsen, K. Schwechheimer, M. L. Rosenblum, W. Cavenee, and B. Vogelstein. 1992. Clonal expansion of p53 mutant cells is associated with brain tumor progression. Nature (Lond.). 355:846-847.

7. Williams, E. D. 1979. The aetiology of thyroid tumors. Clin. Endocrinol. Metab. 8:193-207.

8. Brennan, M. F., and J. S. Macdonald. 1985. Cancer of the endocrine system. In Cancer: Principle and Practice of Oncology. 2nd edition. V. T. De Vita Jr., S. Hellman and S. A. Rosenberg, editors. J. B. Lippincott Co., Philadelphia. $1179-1241$.

9. Sakamoto, A., N. Kasai, and H. Sugano. 1983. Poorly differentiated carcinoma of the thyroid. Cancer. 52:1849-1855.

10. Carcangiu, M. L., G. Zampi, and I. Rosai. 1984. Poorly differentiated ("insular") thyroid carcinoma. Am. J. Surg. Pathol. 8:655-668.

11. Johnson, T. L., R. V. Lloyd, N. W. Thompson, W. H. Beierwalters, and J. C. Sisson. 1988. Prognostic implications of the tall cell variant of papillary thyroid carcinoma. Am. J. Surg. Pathol. 12:22-27.

12. Mizukami, Y., M. Noguki, T. Michigishi, A. Nonomura, T. Hashimoto, S. Otake, S. Nakamura, and F. Matsubara. 1992. Papillary thyroid carcinoma in Kanazawa, Japan: prognostic significance of histological subtypes. Histopathology. 20:243-250.

13. Wright, P. A., E. D. Williams, N. R. Lemoine, and D. Winford-Thomas. 1991. Radiation-associated and 'spontaneous' human thyroid carcinomas show a different pattern of ras oncogene mutation. Oncogene. 6:471-473.

14. Suarez, H. G., J. A. du Villard, M. Severino, B. Caillou, M. Schlumberger, M. Tubiana, C. Parmentier, and R. Monier. 1990. Presence of mutations in all three ras genes in human thyroid tumors. Oncogene. 5:565-570.

15. Shi, Y., M. Zou, H. Schmidt, F. Juhasz, V. Stensky, D. Robb, and N. R. Farid. 1991. High rates of ras codon 61 mutation in thyroid tumors in an iodidedeficient area. Cancer Res. 51:2690-2693.

16. Bongarzone, I., M. A. Pierotti, N. Monzini, P. Mondellini, G. Manenti, R. Donghi, S. Pilotti, M. Grieco, M. Santoro, A. Fusco, et al. 1989. High frequency of activation of tyrosine kinase oncogenes in human papillary thyroid carcinoma. Oncogene. 4:1457-1462.

17. Grieco, M., M. Santoro, M. T. Berlingieri, R. M. Melillo, R. Donghi, I. Bongarzone, M. A. Pierotti, G. Della Porta, A. Fusco, and G. Vecchio. 1990. PTC is a novel rearranged form of the ret proto-oncogene and is frequently detected in vivo in human thyroid papillary carcinomas. Cell. 60:557-563.

18. Santoro, M., F. Carlomagno, I. D. Hay, M. A. Herrmann, M. Grieco, R. Melillo, M. A. Pierotti, I. Bongarzone, G. Della Porta, N. Berger, et al. 1992. Ret oncogene activation in human thyroid neoplasms is restricted to the papillary cancer subtype. J. Clin. Invest. 89:1517-1522.

19. Greco, A., M. A. Pierotti, I. Bongarzone, S. Pagliardini, C. Lanzi, and G. Della Porta. 1992. TRK-T1 is a novel oncogene formed by the fusion of TPR and TRK genes in human papillary thyroid carcinomas. Oncogene. 7:237-242.

20. Klein, R., S. Jing, V. Nanduri, E. O'Rourke, and M. Barbacid. 1991. The trk proto-oncogene encodes a receptor for nerve growth factor. Cell. 65:189-197.

21. Wright, P. A., N. R. Lemoine, P. E. Goretzki, F. S. Wyllie, J. Bond, C. 
Huges, H.-D. Röher, E. D. Williams, and D. Wynford-Thomas. 1991. Mutation of the p 53 gene in a differentiated human thyroid carcinoma cell line, but not in primary thyroid tumors. Oncogene. 6:1693-1697.

22. Ito, T., T. Seyama, T. Mizuno, N. Tsuyama, T. Hayashi, Y. Hayashi, K. Dohi, N. Nakamura, and M. Akiyama. 1992. Unique association of p53 mutations with undifferentiated but not with differentiated thyroid carcinomas of thyroid gland. Cancer Res. 52:1369-1371.

23. Gaidano, G., P. Ballerini, J. Z. Gong, G. Inghirami, A. Neri, E. W. Newcomb, I. T. Margrath, D. M. Knowles, and R. Dalla-Favera. 1991. p53 mutations in human lymphoid malignancies: association with Burkitt lymphoma and chronic lymphocitic leukemia. Proc. Natl. Acad. Sci. USA. 88:5413-5417.

24. Murray, V. 1989. Improved double-stranded DNA sequencing using the linear polymerase chain reaction. Nucleic Acids Res. 17:8889.

25. Hedinger, C., E. D. Williams, and L. H. Sobin. 1988. Histological Typing of Thyroid Tumours. 2nd edition. Springer-Verlag, Inc., New York.

26. Frigo, B., L. Scopsi, C. Patriarca, and F. Rilke. 1991. Silver enhancement of Nickel-diaminobenzidine as applied to single and double immunoperoxidase staining. Biotech. Histochem. 1:159.

27. Gannon, J. V., R. Greaves, R. Iggo, and D. P. Lane. 1990. Activating mutations in $\mathrm{p} 53$ produce a common conformational effect. A monoclonal antibody specific of the mutant form. EMBO (Eur. Mol. Biol. Organ.) J. 9:15951601 .
28. Gerdes, J., M. H. G. Becker, G. Key, and G. Cattoretti. 1992. Immunohistological detection of tumor growth fraction (Ki-67 antigen) in formalin-fixed and routinely processed tissues. $J$. Pathol. 168:85-87.

29. Shi, S.-R., M. E. Key, and K. L. Kalra. 1991. Antigen retrival in formalinfixed, paraffin-embedded tissues: an enhancement method for immunocytochemical staining based on microwave oven heating of tissue sections. J. Histochem. Cytochem. 39:741-748.

30. Carbone, D., I. Chiba, and T. Mitsudomi. 1991. Polymorphism at codon 213 within the p53 gene. Oncogene. 6:1691-1692.

31. Serra, A., G. L. Gaidano, D. Revello, A. Guerrasio, P. Ballerini, R. Dalla Favera, and G. Saglio. 1992. A new polymorphism in the p53 gene. Nucleic Acids Res. 20:928.

32. Wynford-Thomas, D. 1992. p53 in tumor pathology: can we trust immunocytochemistry? J. Pathol. 166:329-330.

33. Venkatesh, Y. S. S., N. G. Ordonez, P. N. Schultz, R. C. Hickey, H. Goepfert, and N. A. Samaan. 1990. Anaplastic carcinoma of the thyroid. Cancer 66:321-330.

34. Ordonez, N. G., A. K. El-Naggar, R. C. Hickey, and N. A. Samaan. 1991. Anaplastic thyroid carcinoma. Am. J. Clin. Pathol. 96:15-24.

35. Hermanek, P., and L. H. Sobin, editors. 1987. TNM Classification of Malignant Tumours. 4th edition. International Union Against Cancer and Springer-Verlag, Inc., New York. 